\title{
Gebrauchte Abkürzungen.
}

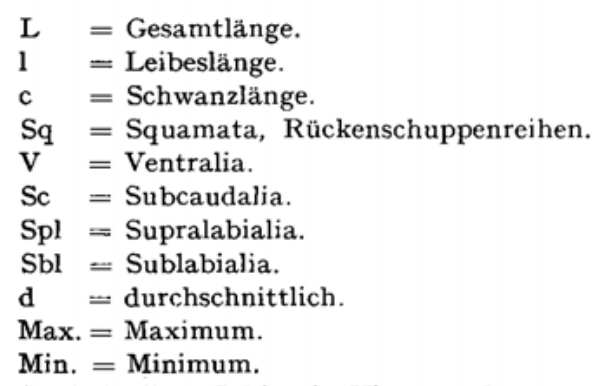

$(5-) 6(-8)=$ Zahlen in Klammer besagen, da $B$ sie bei $7 \%$ und weniger der untersuchten Tiere festgestellt wurden.

$\delta$ ? = die Geschlechtsangabe der Literaturquelle scheint nicht ganz sicher.

(ठ) = eine Geschlechtsangabe fehlt in der angegebenen Literatur, und die Geschlechtsbezeichnung ist Folgerung aus den Zahlen der $\mathrm{V}-\mathrm{Sc}$.

$(\delta ?)=$ wie vorher, aber die Zahlen sind nicht eindeutig, die aus ihnen entnommene Geschlechtsbezeichnung ist also nicht zweifelfrei.

Ortsnamen (Kwangtung; mehrere Jahre unterhaltene Fangstationen):

Dw = Ding wu shan, Westflußgebiet, etwa $23,10^{\circ} \mathrm{n} . \mathrm{Br}$, $112,33^{\circ} \mathrm{ö} . \mathrm{L}$. Lof = Lo fao shan, Ostflußgebiet, etwa $23,16^{\circ} \mathrm{n}$. Br., 112,4 ö. L.

T. c. s. oder $\mathrm{Sg}=$ Tong chung shan und benachbarte Berge bei Sam gong, nahe Lien shan, NW-Kwangtung, etwa $24,5^{\circ} \mathrm{n}$. Br. und III, $5^{\circ} \mathrm{ö}$. L.

Gf = Gao fung $\quad$ Grenzberge zwischen Kwangtung und Hunan,

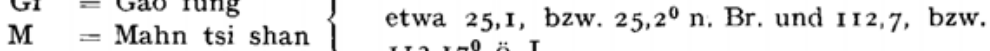

II $3,17^{0}$ ö. L.

$\mathrm{Te}=$ Tsa yuen shan $\mid$ Berggebiete in Nord-Kwangtung, etwa $24,6^{\circ} \mathrm{n}$.

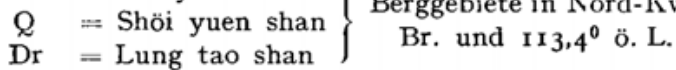

$\mathrm{L}_{\mathrm{p}}=$ Tsat muk ngao, Berge südlich von Lin ping, NNO-Kwangtung, etwa $24,08^{\circ} \mathrm{n}$. Br. und $\mathrm{II}_{4}, 3^{\circ}$ ö. L.

Die beiden erstgenannten sind Regenwaldreste, Te ist Bambuswald, die andern sind subtropische Montanwaldgebiete. 